\title{
The need for a Canadian pain strategy
}

\author{
Mary E Lynch MD FRCP, President, Canadian Pain Society
}

$\mathrm{P}$ in is poorly managed in Canada. This includes acute pain caused by ongoing tissue damage, trauma or surgery, chronic pain and pain related to terminal illness. Reasons for this include under-recognition of the problem, lack of education regarding pain assessment and treatment in graduating health care professionals, and grossly inadequate funding for research regarding pain. Although we have the knowledge and technology, Canadians cannot be sure they will receive adequate or appropriate treatment for pain along the entire continuum of care from community health professionals to specialists in tertiary health care institutions.

The magnitude of the problem is increasing. For example, one in five Canadians experiences chronic pain, children are not spared and the prevalence of chronic pain increases with age $(1,2)$. Many people with diseases such as cancer, HIV and cardiovascular disease are now surviving their acute illness with a resultant increase in quantity of life. However, in many cases, they have poor quality of life due to persistent pain caused either by the ongoing illness or nerve damage caused by the disease even after resolution or cure of the disease. In many cases, pain is also caused by disease treatments such as surgery, chemotherapy or radiotherapy $(3,4)$.

Chronic pain is associated with the worst quality of life compared with other chronic diseases such as chronic lung or heart disease (2). There is double the risk of suicide in chronic pain patients compared with people without chronic pain (5). Higher pain severity is associated with higher suicide rates (6) and a sense of hopelessness (7), and suicide rates remain higher even when controlling for mental illness (8).

A recent review (9) of opioid (narcotic)-related deaths in Ontario, published in the Canadian Medical Association Journal and reported in papers across the country, identified the tragic fact that pain medicationrelated deaths in Ontario are increasing. Even more tragic was the fact that most of the people who died had been seen by a physician within nine to 11 days before death (emergency room visits and office visits) and that the final encounter with the physician involved a mental health or pain-related diagnosis. In almost one-quarter of the cases, the coroner determined that the manner of death was suicide (9). It is tragic that these patients did not get the help that they needed. It is disturbing that in Ontario, the largest province in the country, there is not a single interdisciplinary pain management program that is fully funded by the Ontario Ministry of Health.

At present, wait times for care are greater than one year at more than one-third of publicly funded pain clinics in Canada, with vast areas of the country having no access to appropriate care (10). Patients waiting more than six months from the time of referral to assessment experience deterioration in health-related quality of life, increased pain and increasing depression (11). For this reason, the Canadian Pain Society Task Force on Wait Times determined that wait times for chronic pain conditions beyond six months are medically unacceptable and that, in many cases, six months is far too long to wait for care (12).

\section{UNDERSTANDING PAIN}

The International Association for the Study of Pain taxonomy defines pain as "an unpleasant sensory and emotional experience associated with actual or potential tissue damage or described in terms of such damage" (13). Pain is divided into two broad categories - acute pain, which is associated with ongoing tissue damage, and chronic pain, which is generally understood to be pain that has persisted for longer periods of time.

\section{ACUTE OR PHYSIOLOGICAL PAIN}

Sources of acute pain include work, vehicular, domestic and sports injuries; childbirth; surgery; fractures; burns; and medical procedures. Acute pain is caused by tissue damage, with triggering of the inflammatory response and activation of ascending neural systems that convey pain-related information. These systems are complex and involve numerous signalling relays and feedback loops, and multiple chemical neurotransmitters. We are also equipped with a sophisticated descending modulatory system or 'pain defense network' that enables the body to fight pain. It is this pain defense system that is activated by drugs (eg, opioids) used to treat pain. Acute pain can be controlled using appropriate physical (eg, ice and splinting), pharmacological (eg, anti-inflammatory drugs and opioids) and psychological (eg, reassurance and anxiety management) treatments.

Unfortunately, even in the best hospitals in Canada, patients continue to receive inadequate pain control in emergency rooms and after common surgeries. For example, in a study (14) of postoperative pain control after coronary artery bypass grafting, a common procedure to treat or prevent myocardial infarction, less than $30 \%$ of the ordered dose of pain medication was given, with approximately $50 \%$ of patients continuing to report moderate to severe pain one to five days after surgery. One-quarter of patients rated the pain as 'extremely unpleasant', with significant interference in their ability to function even up to the day before discharge. This included interference with breathing and coughing (critical to prevent postoperative lung infection), general activity and walking. Patients continued to deal with these problems at home 12 weeks later. In another study (15) of patients undergoing ambulatory, 'same-day' shoulder surgery, patients continued to experience severe levels of pain and poor sleep for at least seven days after surgery. At the end of the seven-day study, pain levels still had not decreased, with implications for healing and function. Given that same-day surgery is an increasing phenomenon, it is important to ensure that patients receive effective analgesia for management of the pain at home; this study identified that this is not occurring. More recent work (16) has reported that the situation has not improved.

There is growing evidence that many common surgical procedures are associated with significant rates of persistent postoperative pain. For example, following cardiac surgery, $75 \%$ of patients reported moderate to severe pain at two days, and $54 \%$ at seven days. At three months, approximately $40 \%$ reported persistent nonanginal pain that was moderate to severe and interfered with activities, and at six months this only decreased by $8 \%$, leaving $32 \%$ experiencing chronic pain (16). Following other common surgical procedures, the rates were $30 \%$ to $50 \%$ following amputation, $20 \%$ to $30 \%$ following breast surgery (lumpectomy and mastectomy), 30\% to $40 \%$ following thoracotomy, 10\% following inguinal hernia repair and 10\% following caesarean section (17).

Inadequate pain control is the leading cause of postdischarge visits to the emergency room and early readmission to hospital. Ninety per cent of patients could obtain effective and safe relief of their pain 
with currently available treatments, yet only $50 \%$ gain access to such treatments (18). It is clear that we are not meeting the challenge of optimal pain management for a variety of reasons, including lack of knowledge, values and beliefs that affect judgments, how health care professionals make decisions and use evidence regarding pain management, and lack of prioritization of pain assessment and management on individual and institutional levels (19).

It is critical to treat acute pain not only to decrease suffering but also to maximize healing and minimize the chances of progression to a persistent (chronic) pain condition.

\section{CHRONIC OR PATHOPHYSIOLOGICAL PAIN}

Chronic pain can be associated with other chronic diseases and terminal illnesses, or it may persist after illness or injury. The point at which chronic pain can be diagnosed may vary with the injury or condition that initiated it; however, for most conditions, pain persisting beyond three months is reasonably described as a chronic pain condition.

Pain research in the past four decades has increased our understanding of the underlying mechanisms of chronic pain, now understood to involve a neural response to tissue injury. In other words, peripheral and central events related to disease or injury can trigger long-lasting changes in peripheral nerves, spinal cord and brain such that the system becomes sensitized and capable of spontaneous activity or of responding to non-noxious stimuli, which results in pain. In this case, pain persists beyond the point where normal healing takes place and is often associated with abnormal sensory findings.

Traditionally, clinicians have conceptualized chronic pain as a symptom of disease or injury. Treatment was focused on addressing the underlying cause with the expectation that the pain would then resolve. It was believed that the pain itself could not kill. We now know that the opposite is true. Pain persists beyond injury and there is mounting evidence that 'pain can kill'. In addition to contributing to ongoing suffering, disability and diminished quality of life, it has been demonstrated that uncontrolled pain compromises immune function, promotes tumour growth and can compromise healing, with an increase in morbidity and mortality following surgery $(20,21)$, as well as a decrease in the quality of recovery (22). Clinical studies suggest that prolonged, untreated pain suffered early in life may have long-lasting effects that extend to persistent changes in sensory processing with implications for pain experienced later in life (23).

Chronic pain has major implications for the individual suffering from pain and for family and loved ones who become involved in the suffering person's challenges. The workplace suffers through loss of productive employees, the community is deprived of active citizens, and the economic costs of caring for those suffering from chronic pain are dramatic.

\section{CHILDREN}

As recently as 20 years ago, many people believed that because children did not have fully developed nervous systems they did not experience pain as much as adults. This belief led to a situation in which infants and children were not provided with appropriate pain relief when undergoing painful procedures. Research has demonstrated that this is inaccurate. Even premature neonates experience pain, and this pain is associated with physiological changes (eg, respiratory and heart rate) and specific behavioural changes (eg, specific facial expression and crying) that can be used in the assessment and treatment of pediatric pain (24). The prevalence of recurring or persistent pain in children is $15 \%$ to $30 \%$ (25). Recurrent and chronic pain leads to significant interference with daily functioning, is associated with poor school performance (26) and may increase the risk of experiencing chronic pain in adulthood $(27,28)$. Children with pain also experience more mental health problems. It is a priority to address pain in children, yet there are only five centres with dedicated pain management facilities for children in Canada (29); thus, most children in Canada do not have access to best-practice care for management of pain.

\section{AGING POPULATIONS}

Pain is also a major concern among older adults because of its high prevalence, which is estimated to be as high as $65 \%$ for those living in the community and up to $80 \%$ for those living in long-term care facilities. By the year 2036, one in four Canadians will be older than 65 years of age, compounding the problem of pain management in old age (30). Well-documented undertreatment and underassessment of pain among older adults reflect systemic failures to adequately address the needs of this rapidly increasing segment of the population and represent one of the most pressing ethical concerns of pain clinicians $(31-33)$.

\section{CANCER AND HIV SURVIVORS}

As medical technology improves, many people with previously fatal conditions such as cancer and HIV are surviving to live longer lives. The introduction of combination antiretroviral therapy in the mid 1990s has dramatically reduced morbidity and mortality associated with HIV among patients with access to treatment. The incidence of HIV sensory neuropathy (HIV-SN) has been rising (4). This pain condition is due to nerve damage caused by the virus itself and the treatments for HIV because many of the treatments are toxic to nerves. Recent estimates of the prevalence of HIV-SN range from 20\% to 50\%. In Canada, the most recent figures indicate that the number of people living with HIV (including AIDS) continues to rise from an estimated 57,000 in 2005 to 65,000 in 2008 (a 14\% increase; Canada AIDS Committee Toronto, www.actoronto.org/home.nsf/pages/hivaidsstatscan). This means that there are more than 25,000 people with HIV-SN in Canada now and this will increase annually. The increase will be due to new infections and the increased risk of developing HIV-SN as the duration of the disease progresses in those already infected.

The situation with cancer survivors is very similar $(34,35)$. Recent reviews have identified that nearly one-half of cancer pain is undertreated (36). This is a growing, under-recognized and undertreated problem. The most frequent cause is neuropathic pain caused by surgery, chemotherapy or radiotherapy. Management of chronic pain must be integrated into comprehensive cancer care so that cancer survivors can fully enjoy their life (35).

\section{THE TREATMENT NEED}

The best method of treating acute pain is to assess pain and treat effectively as soon as pain is apparent. A useful concept is to consider pain the 'fifth vital sign'. In other words, as medical staff monitor the patient's pulse, blood pressure, respiration and heart rate, they should also assess and treat pain. If pain can be anticipated based on the expected procedure (eg, surgery, bone marrow aspiration, and needle stick in the eye for certain ophthalmological procedures), then effective pain treatment and sedation should be offered before the procedure starts. Treatment may include early, effective use of pain-relieving medications from the anti-inflammatory and opioid (narcotic) categories, with use of additional pain-relieving medications or sedatives and local or regional anesthetic blocks as appropriate (37).

Treatment of chronic pain should span the continuum of selfmanagement up to and including access to full interdisciplinary pain management teams, depending on the type of pain and the level of complexity. Interdisciplinary teams are required because chronic pain may lead to significant limitations in the ability to pursue work in the wage-earning workforce, one's roles in relationships and to care for children or others. This may also lead to an emotional response with resultant anxiety, depression or self-medication, which may lead to substance dependency and addiction disorders (38).

\section{THE EDUCATIONAL NEED}

A recent survey (39) of prelicensure pain curricula in health science and veterinary training programs across Canada identified inadequate training regarding pain among health care practitioners. This survey included medical schools and faculties that train nurses, dentists, physiotherapists and occupational therapists, as well as veterinary 
medicine programs. Only one-third of the programs could identify time designated for mandatory teaching about pain. The mean total number of hours designated for pain teaching over the entire academic training program was 15 for dentistry, 16 for medicine, 31 for nursing, 28 for occupational therapy, 13 for pharmacy, 41 for physical therapy and 87 for veterinarians (39). In other words, veterinarians receive five times more education for pain than physicians. Therefore, it is not surprising that when people in pain present to their community practitioners for help, these family physicians or, in some cases, nurse practitioners (where they are available) are not well equipped to help them. This is also true about the education of specialists with implications for pain care following painful medical procedures, trauma or surgery.

\section{THE RESEARCH NEED}

Research for pain is grossly underfunded in Canada considering the burden of illness. The Canadian Pain Society conducted a survey (40) of pain research funding in Canada. Of 79 active researchers conducting pain-related studies, 65 received funding in the past five years amounting to a total of $\$ 80.9$ million. This is less than $1 \%$ of total funding provided by the Canadian Institutes for Health Research, and only $0.25 \%$ of the funding for all health research (40). The authors found that only six randomized controlled trials that examined treatments for pain were funded by the Canadian Institutes for Health Research from 1999 to 2009, and only two of these involved chronic pain (personal communication).

Statistics Canada reported that total spending on research and development in the health field amounted to $\$ 6.3$ billion for 2007 (Statistics Canada, 2008). Considering the overall burden of pain in Canada, pain research is underfunded. A rough comparison between cancer and chronic pain is instructive. According to the latest available estimates (Health Canada, 2002), the cost of direct health care for cancer was approximately $\$ 2.5$ billion per year in 1998 . The total amount of research funding for cancer in 2008 was $\$ 390$ million (Canadian Cancer Research Alliance, 2008). Using these figures, the ratio of research dollars to direct health care costs would be approximately 41 times higher for cancer than for chronic pain. Pain research is comparatively grossly underfunded.

\section{PAIN COSTS CANADA}

Chronic pain is costly not only to the patient but also to society as a whole. Expenditures on chronic pain include both direct costs related to treatment and provision of health care services, and indirect costs such as those associated with loss of productivity, lost tax revenues and disability payments. Uncontrolled pain continues to be the single most common cause of disability among working-age adults in Canada (41). Sixty per cent of people with chronic pain eventually lose their job, incur loss of income or will have a reduction in responsibilities as a result of their pain. For people who are still employed, it is anticipated that they will have a mean of 28.5 lost work days per year

\section{REFERENCES}

1. Moulin D, Clark AJ, Speechly M, Morley-Forster P. Chronic pain in Canada - prevalence, treatment, impact and the role of opioid analgesia. Pain Res Manage 2002;7:179-84.

2. Choiniere M, Dion D, Peng P, et al. The Canadian STOP-PAIN Project - Part 1: Who are the patients on the waitlists of multidisciplinary pain treatment facilities? Can J Anesth 2010;57:539-48.

3. McGillion M, L'Allier PL, Arthur H, et al. Recommendations for advancing the care of Canadians living with refractory angina pectoris: A Canadian Cardiovascular Society position statement. Can J Cardiol 2009;25:399-401.

4. Phillips TJC, Cherry CL, Moss PJ, Rice ASC. Painful HIV-associated sensory neuropathy. Pain Clinical Updates 2010;XVIII:1-8.

5. Tang N, Crane C. Suicidality in chronic pain: Review of the prevalence, risk factors and psychological links. Psychol Med 2006;36:575-86.
Chronic pain costs more than cancer, heart disease and HIV combined. Estimates place direct health care costs for Canada at more than $\$ 6$ billion per year, and productivity costs related to job loss and sick days at $\$ 37$ billion per year $(2,42)$. Patients are referred to pain clinics when first-line treatments are not available, or when severe unremitting pain and/or complex psychosocial situations exist. The economic burden of patients who wait for access to pain clinics was studied by the Canadian STOP-PAIN Research Group. They reported that patients waiting to access pain clinics spent a median of $\$ 17,544$ per year, the vast majority of which were indirect expenditures, eg, lost labour time and funding of private health care treatments. This demonstrates the significant financial burden that pain has on the individual as well as our society $(2,43)$.

\section{THE INTERNATIONAL INITIATIVE}

The International Association for the Study of Pain hosted the first International Pain Summit on September 3, 2010, in Montreal, Quebec. More than 250 representatives from 84 countries, and professional and human rights organizations endorsed that access to pain management is a fundamental human right and contributed to the Declaration of Montreal. The declaration recognized the intrinsic dignity of all persons and the right of access to pain management without discrimination, and the obligation of governments and health care institutions to establish laws, policies and systems that will help to promote - and will certainly not inhibit - the access of people in pain to fully adequate pain management. It was further acknowledged that failure to establish such laws, policies and systems is unethical and a breach of the human rights of people harmed as a result.

It is essential that Canada takes a leading role in embracing the Declaration of Montreal and shows the rest of the world that it is possible to treat our citizens with the compassion and dignity that they deserve.

\section{SUMMARY}

Pain is undertreated in Canada and there are major problems with access to appropriate care for all types of pain. A national pain strategy addressing educational, clinical and research needs is required. Following the recent International Pain Summit and the creation of the Declaration of Montreal, which identified that access to pain management is a fundamental human right, it is essential that Canada takes a leading role in proceeding with a national pain strategy and demonstrates to Canadians and the rest of the world that it is possible to treat our citizens with the compassion and dignity that they deserve. Following work started by the Canadian Pain Society Task Force on Service Delivery, the Canadian Pain Society and the Canadian Pain Coalition are in the process of leading a Canadian Pain Strategy and Canadian Pain Summit scheduled for spring 2012. A website will soon be available with further information about how you can get involved. Stay tuned.
6. Kikuchi N, Obmori-Matsuda K, Shimazu T, et al. Pain and risk of completed suicide in Japanese men: A population based cohort study in Japan. J Pain Symptom Manage 2008;37:316-24.

7. Fishbain DA, Goldberg M, Rosonoff RS, Rosonoff $\mathrm{H}$. Completed suicide in chronic pain. Clin J Pain 1991;7:29-36.

8. Ratcliffe GE, Enns MW, Belik S, Sareen J. Chronic pain conditions and suicidal ideation and suicide attempts: An epidemiologic perspective. Clin J Pain 2008;24:204-10.

9. Dhalla IA, Mamdani MM, Sivilotti MLA, Kopp A, Qureshi O, Juurlink DN. Prescribing of opioid analgesics and related mortality before and after the introduction of long-acting oxycodone. CMAJ 2009;181:891-6.

10. Peng P, Choiniere M, Dion D, et al. Challenges in accessing multidisciplinary pain treatment facilities in Canada. Can J Anesth 2007;54:977-84. 
11. Lynch ME, Campbell FA, Clark AJ, et al. A systematic review of the effect of waiting for treatment for chronic pain. Pain 2008;136:97-116.

12. Lynch ME, Campbell FA, Clark AJ, et al. Waiting for treatment for chronic pain - a survey of existing benchmarks: Toward establishing evidence-based benchmarks for medically acceptable waiting times. Pain Res Manage 2007;12:245-8.

13. Merskey H, Bogduk N. Classification of Chronic Pain. Seattle: IASP Press, 1994.

14. Watt-Watson J, Stevens B, Katz J, Costello J, Reid GJ, David T. Impact of preoperative education on pain outcomes after coronary artery bypass graft surgery. Pain 2004;109:73-85.

15. Watt-Watson J, Chung F, Chan VW, McGillion M. Pain management following discharge after ambulatory same-day surgery. J Nurs Manage 2004;12:153-61.

16. Watt-Watson J, Choiniere M, Costello J, et al. Prevalence, characteristics and risk factors of persistent post-operative pain after cardiac surgery. World Congress on Pain. Montreal, August 29 to September 2, 2010. (Abst)

17. Kehlet H, Jensen TS, Woolf CJ. Persistent postsurgical pain: Risk factors and prevention. Lancet 2006;367:1618-25.

18. Cousins MJ. National Pain Strategy. Australian National Pain Summit Initiative 2009. <www.painsummit.org.au/strategy/ national-pain-strategy.html> (Accessed on March 3, 2011).

19. Seers K, Watt Watson J, Bucknall T. Challenges of pain management for the 21st century. J Advanced Nursing 2006;55:4-6.

20. Liebeskind JC. Pain can kill. Pain 1991;44:3-4.

21. Page GG. Acute pain and immune impairment. Pain Clinical Updates 2005;XIII:1-4

22. Wu CL, Rowlingson AJ, Partin AW, et al. Correlation of postoperative pain to quality of recovery in the immediate postoperative period. Reg Anesth Pain Med 2005;30:516-22.

23. Finley GA, Franck LS, Grunau RE, von Baeyer CL. Why children's pain matters. Pain Clinical Updates 2005;XIII:1-6.

24. McGrath PJ, Stinson JN. Measurement and assessment of pain in pediatric patients. In: Lynch ME, Craig KD, Peng PWH, eds. Clinical Pain Management: A Practical Guide. West Sussex, UK: Blackwell Publishing Ltd, 2011:64-71.

25. Stanford EA, Chambers CT, Biesanz JC, Chen E. The frequency, trajectories and predictors of adolescent recurrent pain: A population based approach. Pain 2008;138:11-21.

26. Gauntlett-Gilbert J, Eccleston C. Disability in adolescents with chronic pain: Patterns and predictors across different domains of functioning. Pain 2007;131:132-41.

27. Palermo TM, Koh JL, Zeltzer LK. Pain in children. In: Lynch ME, Craig KD, Peng PWH, eds. Clinical Pain Management: A Practical Guide. West Sussex, UK: Blackwell Publishing Ltd, 2011:319-25.
28. Jones GT, Power C, MacFarlane GJ. Adverse events in childhood and chronic widespread pain in adult life: Results from the 1958 British Birth Cohort Study. Pain 2009;143:92-6.

29. Peng P, Stinson J, Choiniere M, et al. Dedicated multidisciplinary pain management centers for children in Canada: The current status. Can J Anesth 2007;55:985-51.

30. Statistics Canada. Population projections: Canada, the provinces and territories, 2010. <www.statcan.gc.ca/daily-quotidien/100526/ dq100526b-eng.htm> (Accessed on March 1, 2011).

31. Hadjistavropoulos T, Marchildon GP, Fine PG, et al. Transforming long-term care pain management in North America: The policy-clinical interface. Pain Med 2009;10:429-31.

32. Hadjistavropoulos T, Herr K, Turk DC, et al. An interdisciplinary expert consensus statement on assessment of pain in older persons. Clin J Pain 2007;23(1 Suppl):S1-S43.

33. Ferrell BR, Novy D, Sullivan MD. Ethical dilemmas in pain management. J Pain 2001;2:171-80.

34. Moryl N, Coyle N, Essandoh S, Glare P. Chronic pain management in cancer survivors. J Natl Compr Canc Netw 2010;8:1104-10.

35. Levy MH, Chwistek M, Mehta RS. Management of chronic pain in cancer survivors. Cancer J 2008;14:401-9.

36. Deandrea S, Montanari M, Moja L, Apolone G. Prevalence of undertreatment of cancer pain. Ann Oncology 2008;19:1985-91.

37. MacIntyre P, Scott DA, Schug SA, Visser EJ, Walker SM. Acute Pain Management: Scientific Evidence, 3rd edn. Sydney, Australia: ANZCA, 2010.

38. Lynch ME. Introduction to management. In: Lynch ME, Craig KD, Peng PWH, eds. Clinical Pain Management: A Practical Guide. West Sussex, UK: Blackwell Publishing Ltd, 2011:91-5.

39. Watt-Watson J, McGillion M, Hunter J, et al. A survey of prelicensure pain curricula in health science faculties in Canadian universities. Pain Res Manage 2009;14:439-44.

40. Lynch ME, Schopflocher D, Taenzer P, Sinclair C. Research funding for pain in Canada. Pain Res Manage 2009;14:113-5.

41. Statistics Canada - Housing, Family and Social Statistics Division. A profile of disability in Canada. Statistics Canada, 89-577-XIE, 1-24.2001.

42. Phillips CJ, Schopflocher D. The Economics of Chronic Pain. In: Rashiq S, Taenzer P, Schopflocher D, eds. Health Policy Perspectives on Chronic Pain. Weinheim: Wiley Press, 2008.

43. Guerriere D, Choiniere M, Dion D, et al. The Canadian STOP-PAIN Project - Part 2: What is the cost of pain for patients on the waitlists of multidisciplinary pain treatment facilities? Can J Anesth 2010;57:549-58. 


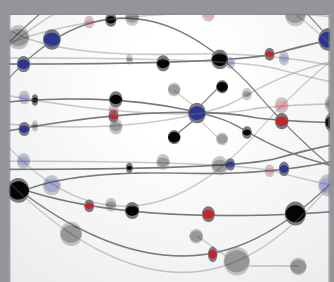

The Scientific World Journal
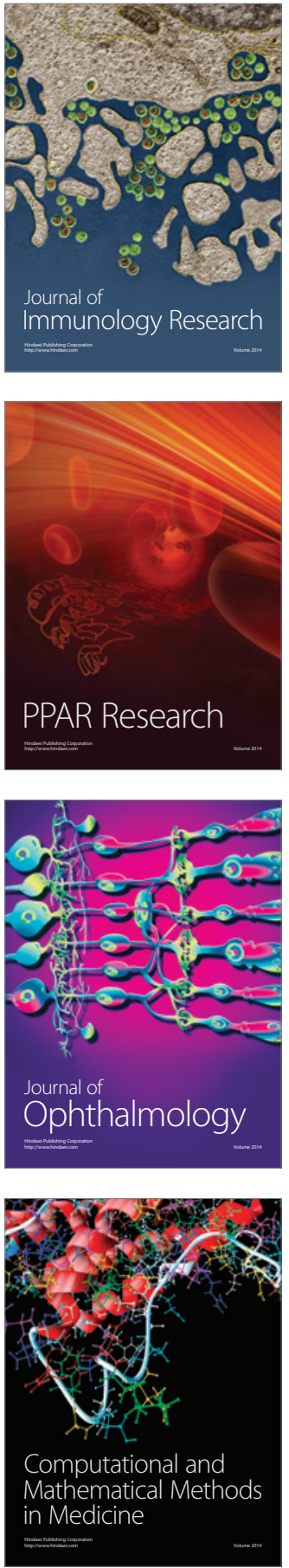

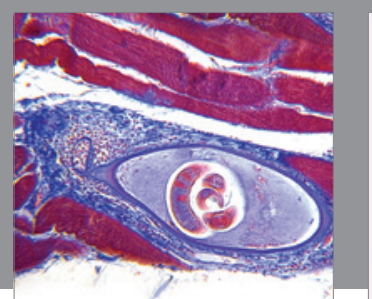

Gastroenterology Research and Practice

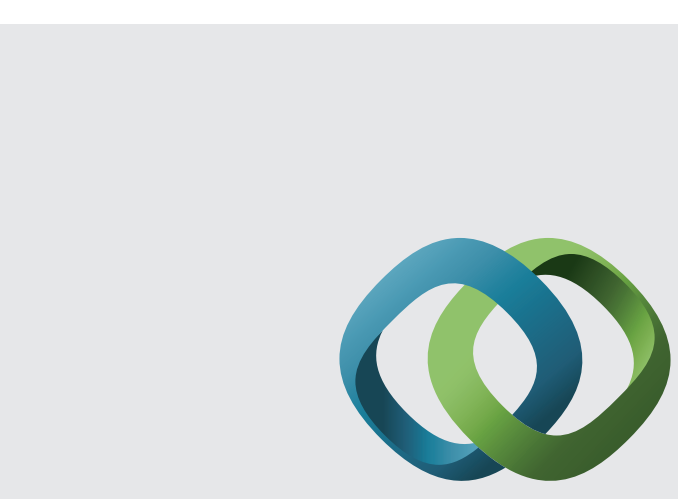

\section{Hindawi}

Submit your manuscripts at

http://www.hindawi.com
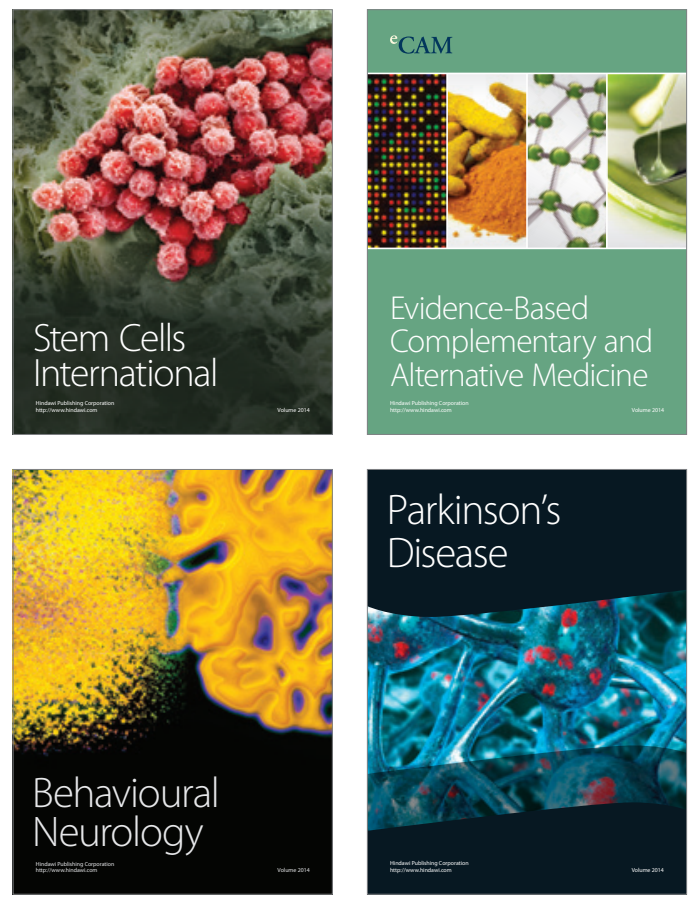


Disease Markers
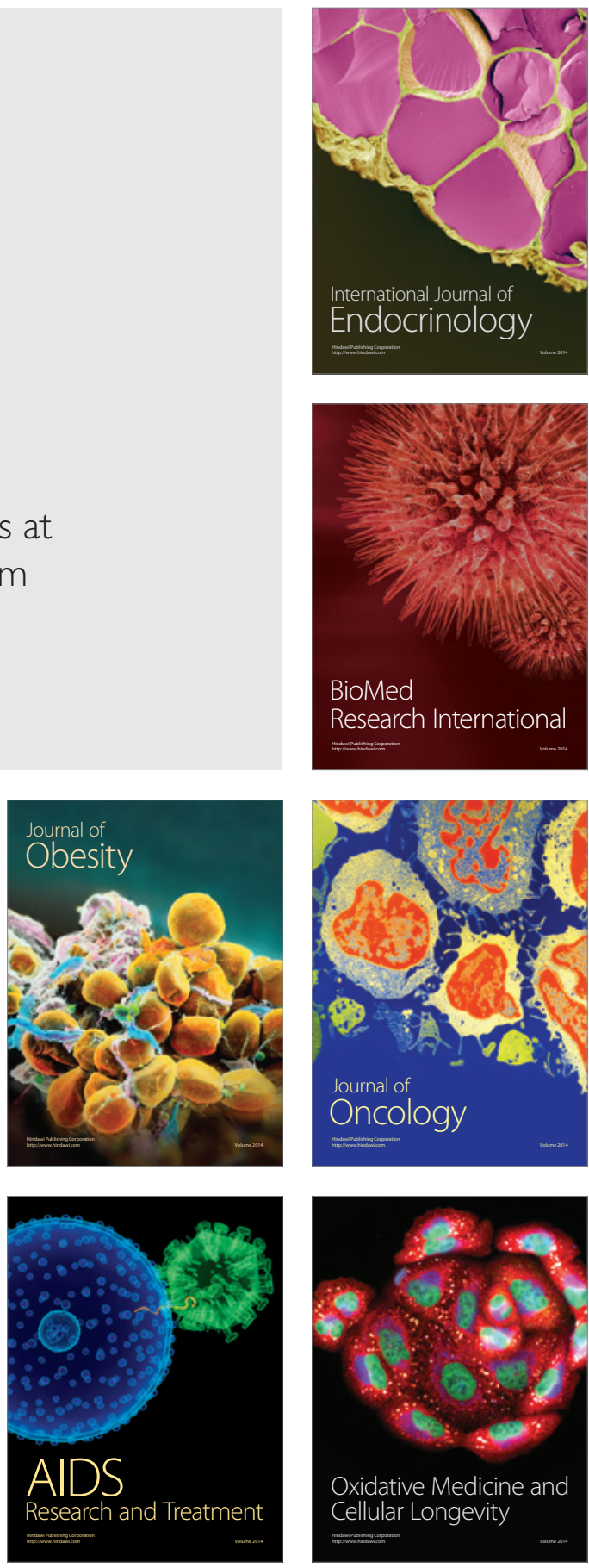